University of Nebraska - Lincoln

DigitalCommons@University of Nebraska - Lincoln

Biological Systems Engineering: Papers and

Publications

Biological Systems Engineering

2004

\title{
Changes in composition and thermal transition temperatures of grain sorghum wax during storage
}

\author{
Keum Taek Hwang \\ Chonbuk National University, South Korea \\ Curtis L. Weller \\ University of Nebraska-Lincoln, cweller1@unl.edu \\ Susan L. Cuppett \\ University of Nebraska-Lincoln, scuppett1@unl.edu \\ Milford Hanna \\ University of Nebraska-Lincoln, mhanna1@unl.edu
}

Follow this and additional works at: https://digitalcommons.unl.edu/biosysengfacpub

Part of the Biological Engineering Commons

Hwang, Keum Taek; Weller, Curtis L.; Cuppett, Susan L.; and Hanna, Milford, "Changes in composition and thermal transition temperatures of grain sorghum wax during storage" (2004). Biological Systems Engineering: Papers and Publications. 112.

https://digitalcommons.unl.edu/biosysengfacpub/112

This Article is brought to you for free and open access by the Biological Systems Engineering at DigitalCommons@University of Nebraska - Lincoln. It has been accepted for inclusion in Biological Systems Engineering: Papers and Publications by an authorized administrator of DigitalCommons@University of Nebraska Lincoln. 


\title{
Changes in composition and thermal transition temperatures of grain sorghum wax during storage
}

\author{
Keum Taek Hwang, ${ }^{1}$ Curtis L. Weller, ${ }^{2}$ Susan L. Cuppett, ${ }^{3}$ and Milford A. Hanna ${ }^{4}$ \\ ${ }^{1}$ Department of Food Science and Human Nutrition, Institute for Molecular Biology and Genetics, \\ Chonbuk National University, Jeonju, Jeonbuk 561-756, South Korea \\ ${ }^{2}$ Department of Biological Systems Engineering, University of Nebraska-Lincoln, Lincoln, NE 68583-0726, USA \\ ${ }^{3}$ Department of Food Science and Technology, University of Nebraska-Lincoln, Lincoln, NE 68583-0919, USA \\ ${ }^{4}$ Industrial Agricultural Products Center, University of Nebraska-Lincoln, Lincoln, NE 68583-0730, USA \\ Corresponding author - C. L. Weller, tel 402 472-9337, fax 402 472-6338, email cweller1@unl.edu
}

\begin{abstract}
Grain sorghum (Sorghum bicolor) wax is composed mainly of aldehydes, alcohols, and acids. Aldehydes, comprising about one-half of the wax, are readily converted to acids in presence of air. In this study, whole sorghum wax and an aldehyde fraction from sorghum wax were subjected to oxidative conditions. Changes in the major components and thermal transition temperatures were determined using HPLC and differential scanning calorimeter (DSC), respectively. The aldehyde fraction was oxidized markedly to acids over 4 months in storage at room temperature. Acid content, in the fraction, was initially 5-7\% and increased to $42-$ $51 \%$ after 135 days in storage. Consequently, thermal transition apex and end temperatures of the fraction, which were initially $73-74$ and $76-77^{\circ} \mathrm{C}$, respectively, increased to $80-81$ and $83-85^{\circ} \mathrm{C}$, respectively, after 135 days. Whole sorghum wax, composed initially of $55 \%$ aldehydes, $37 \%$ alcohols, and $7 \%$ acids, slightly increased acid level to $8-12 \%$ during storage over 5 months under various conditions. Thermal transition temperatures of the wax changed little over all storage conditions during 5 months of storage with $83-84{ }^{\circ} \mathrm{C}$ for apex temperatures and $86-87^{\circ} \mathrm{C}$ for end temperatures.
\end{abstract}

Keywords: aldehyde, composition, grain sorghum wax, melting point, storage, transition temperature

\section{Introduction}

About $0.2 \%$ of grain sorghum (Sorghum bicolor) can be recovered as wax by extraction with hexane (LochteWatson et al., 1999). Wax extracted from grain sorghum has been noted to have physical properties similar to carnauba wax (Weller et al., 2000). Carnauba wax is a major imported vegetable wax in the United States and other countries. Carnauba wax is used in various industries to manufacture polishing wax (cars, shoes, floors, etc.), paper and packaging materials, paints, cosmetics (lipsticks, enamels, etc.), foods (bubble gum, chocolate, fruit and vegetable coatings, cheese coatings, etc.), and pharmaceutical products. 
Carnauba wax is known to be mostly composed of wax esters (84-85\%) (Hamilton, 1995a). However, the chemistry of grain sorghum wax is not fully defined. Until recently, studies on the chemical composition of grain sorghum wax, with the first published around 1950, were not in agreement (Bunger and Kummerow, 1951; Cannon and Kummerow, 1957; Dalton and Mitchell, 1959; Seitz, 1977; Bianchi et al., 1979; Avato et al., 1990). Only Bianchi et al. (1979) and Avato et al. (1990), among the references listed, reported that aldehydes were one of the major components in grain sorghum wax. Hwang et al. (2002a) recently confirmed that the major components in the sorghum wax were aldehydes, alcohols, and acids. Their studies indicated that the major components of grain sorghum wax were not wax esters, compounds that have been traditionally considered as wax. In particular, high concentration of aldehydes is a unique chemical characteristic of grain sorghum wax.

HPLC has not been widely used to analyze waxes due to the low solubility of the waxes in solvents at room temperature, the lack of UV-detectable materials in the waxes, and the difficulties in separation of the components (Hamilton, 1995b). Hwang et al. (2002b) developed an HPLC method using a silica column and an evaporative light scattering detector (ELSD) to analyze the major components of sorghum wax. They reported that grain sorghum wax was composed of $46 \%(\mathrm{w} / \mathrm{w})$ aldehydes, $41 \%$ alcohols and $8 \%$ acids. Aldehydes were not detected in carnauba wax (Hwang et al., 2002b).

Aldehydes in grain sorghum wax are expected to be easily oxidized to form acids when exposed to air before and after application of the wax on various surfaces, whereas the other components are stable. Autoxidation of aldehydes to acids in sorghum wax is different from the traditional autoxidation in highly unsaturated lipids, which typically affects rancidity, odor, and flavor of lipid-containing materials. Because aldehydes in the wax are mostly long-chained, the converted acids are not expected to affect odor and flavor. Also, because the wax most likely consists of saturated compounds (Bianchi et al., 1979; Avato et al., 1990), the traditional autoxidation usually taking place around double bonds is not likely to occur.

Oxidation of the aldehydes in the wax may alter the composition of the wax by conversion of the al- dehydes to acids. Thermal transition temperature of an aldehyde is lower than that of an alcohol or acid with the same number of carbons (Linstromberg and Baumgarten, 1974). Consequently, the oxidation of the aldehydes may affect the thermal transition temperatures of the wax.

In this study, grain sorghum wax and an aldehyde fraction from the wax were stored in contact with air under various storage conditions. Determination of changes in composition and thermal transition temperatures of the sorghum wax and its component aldehydes under these various conditions was the objective of this study.

\section{Materials and methods}

\subsection{Materials}

The grain sorghum was Golden Harvest H512, grown and harvested in the 1996 and 1999 crop years in Nebraska. Carnauba wax (T-1) was obtained from Strohmeyer \& Arpe Co., Inc. (Short Hills, NJ).

\subsection{Extraction of wax from grain sorghum}

Wax was extracted and collected from 10 subsamples of grain sorghum as previously reported (Hwang et al., 2002a). Washed and dried grain sorghum $(800 \mathrm{~g})$ was refluxed with $800 \mathrm{ml}$ hexane for $30 \mathrm{~min}$. The contents were filtered through coffee filter paper lying on top of a Whatman no. 2 filter paper. The filtrate was placed in a $-18{ }^{\circ} \mathrm{C}$ freezer for at least $8 \mathrm{~h}$. Wax precipitate was collected by filtering the cold miscella with a Whatman no. 42 filter paper and desolvented under vacuum. Three subsamples of the collected wax were evaluated for composition, two subsamples were evaluated for thermal transition temperatures, and five subsamples underwent fractionation.

\subsection{Fractionation of grain sorghum wax components}

Major grain sorghum wax components were fractionated and collected from subsamples of the collected wax using column chromatography (Hwang et al., 2002a) with silica gel (particle diameter: 2-25 $\mu \mathrm{m}$; average pore diameter: $60 \AA$, Aldrich, Milwaukee, WI). 
The eluting solvent mixtures were applied on the column in the sequence of $50 \mathrm{ml}$ hexane, $30 \mathrm{ml}$ hexane: chloroform (containing 0.75\% ethanol) (29:1), $30 \mathrm{ml}$ hexane:chloroform (5:1), $60 \mathrm{ml}$ hexane:chloroform (1:1), $30 \mathrm{ml}$ hexane:chloroform (1:2), $180 \mathrm{ml}$ chloroform, $102 \mathrm{ml}$ chloroform:acetic acid (50:1), $84 \mathrm{ml}$ chloroform:acetic acid (20:1), and $100 \mathrm{ml}$ methanol. Fractions were identified using TLC (silica gel, $20 \mathrm{~cm}$ $\times 20 \mathrm{~cm}$, particle size: $250 \mu \mathrm{m}$, Aldrich) with a developing solvent of hexane:diethyl ether:acetic acid (85:15:2) following a previous report (Hwang et al., 2002a). The fractions were stored in the eluted solvent at $-18{ }^{\circ} \mathrm{C}$. Solvent in the fractions was removed using a nitrogen stream before storage trials. Three subsamples of collected aldehyde fraction were evaluated for composition and two subsamples were evaluated for thermal transition temperatures.

\subsection{Storage of aldehyde fraction of sorghum wax and whole sorghum wax}

The aldehyde fraction was redissolved in hexane (Ald-Hex) or chloroform (Ald-Chl). The solvent was removed using a nitrogen stream. It was stored at room temperature, in sunlight, for up to 135 days. Grain sorghum wax samples were stored at room temperature and at an elevated temperature $\left(45^{\circ} \mathrm{C}\right.$ \pm 1.0 ). For the room temperature sample, a part was stored in the dark (Wax-R-D) for up to 161 days and the other part was stored in the dark for 15 days and exposed to sunlight (Wax-R-S) for another 146 days. For the elevated temperature sample, one part was stored at $45^{\circ} \mathrm{C}$ in the dark (Wax-A-H) for up to 161 days. The other part was stored at $45^{\circ} \mathrm{C}$ in the dark for 25 days and redissolved with chloroform on the 25th day followed by solvent removal using a nitrogen stream. This was re-stored again at $45^{\circ} \mathrm{C}$ in the dark (Wax-A-C) for another 136 days. Storage of sorghum wax for 5 months was anticipated to be enough time to monitor the changes in composition and transition temperatures of the wax as related to quality because 5 months is an acceptable period for storage and transportation of wax after extraction before use. The storage conditions for the samples are summarized in Table 1.

\subsection{HPLC of sorghum wax}

The major components in sorghum wax were determined using HPLC as previously reported (Hwang et al., 2002b): Two Waters 510 HPLC pumps (Waters Corp., Milford, MA) were operated in gradient modes using mixtures of hexane, methyl tert-butyl ether and acetic acid as mobile phases. Flow rate of

Table 1. Extraction methods and storage conditions of sorghum wax samples

\begin{tabular}{|c|c|c|c|c|c|}
\hline Sample & $\begin{array}{l}\text { Sample } \\
\text { code }\end{array}$ & Pretreatment & \multicolumn{3}{|l|}{ Storage condition } \\
\hline $\begin{array}{l}\text { Aldehyde fraction separated } \\
\text { from grain sorghum wax using } \\
\text { column chromatography }\end{array}$ & Ald-Hex & $\begin{array}{l}\text { Dried fraction was redissolved } \\
\text { in hexane, and the solvent was } \\
\text { evaporated }\end{array}$ & Room temperature & Sunlight & Up to 135 days \\
\hline \multirow{2}{*}{$\begin{array}{l}\text { Grain sorghum wax } \\
\text { (extracted using hexane) }\end{array}$} & Wax-R-D & Dried powder wax & Room temperature & Dark & Up to 161 days \\
\hline & Wax-R-S & $\begin{array}{l}\text { Dried powder wax was stored } \\
\text { in dark at room temperature } \\
\text { for } 15 \text { days }\end{array}$ & Room temperature & Sunlight & $\begin{array}{l}\text { Up to another } \\
146 \text { days }\end{array}$ \\
\hline
\end{tabular}


mobile phase was $1 \mathrm{ml} / \mathrm{min}$. Column was a Luna $5 \mu$ silica column $(250 \mathrm{~mm} L \times 4.6 \mathrm{~mm}$ i.d.; Phenomenex, Torrance, CA) connected to a guard column (4 mm $L \times 3 \mathrm{~mm}$ i.d. silica cartridge in a SecurityGuard cartridge system; Phenomenex). The column and guard column were heated at $40{ }^{\circ} \mathrm{C}$ using a Waters column heater module. Exposed lines from injection loop to detector connection were maintained at about 38$40{ }^{\circ} \mathrm{C}$ using a wrapped heating tape. The detector was a Varex ELSD II (Rockville, MD) operated at $50^{\circ} \mathrm{C}$ with nitrogen pressure of $930 \mathrm{kPa}$. All the standards and samples were dissolved in hexane and $100 \mu \mathrm{l}$ of each injected.

\subsection{Determination of thermal transition temperatures}

Thermal transition temperatures of sorghum wax and the major fractions of the wax were measured using a Pyris 1 Perkin-Elmer differential scanning calorimeter (DSC) (Norwalk, CT) according to ASTM D 4419-90 (ASTM, 2000) with minor modification as follows: $10 \mathrm{mg}$ ( $\pm 1 \mathrm{mg})$ of sample were weighed in an aluminum pan (Part No. 122292 and 100793; TA Instruments, New Castle, DE). The sample pan and an empty reference pan were placed in the DSC sample and reference compartments. The test cell was precycled by holding it for $1 \mathrm{~min}$ at $30^{\circ} \mathrm{C}$, heating it from 30 to $105^{\circ} \mathrm{C}$ at $10^{\circ} \mathrm{C} / \mathrm{min}$, and cooling it to $30^{\circ} \mathrm{C}$ at $10^{\circ} \mathrm{C} / \mathrm{min}$. After holding the test cell for $1 \mathrm{~min}$ at $30{ }^{\circ} \mathrm{C}$, it was heated from 30 to $105^{\circ} \mathrm{C}$ at $10^{\circ} \mathrm{C} / \mathrm{min}$ and held for $1 \mathrm{~min}$ at $105^{\circ} \mathrm{C}$. DSC curve of the last heating cycle was recorded. Transition peak apex temperature was obtained by the intersection of tangents to slopes of the largest peak. The onset and end temperatures were located by the intersection of the peak tangents with the base line.

\subsection{Statistical analysis}

Composition values of the aldehyde fractions and the waxes were means of three determinations. Thermal transition temperatures were means of two determinations. For aldehyde fraction means, between-subjects effects were observed with a two treatments for 5 days factorial design and the means in each treatment were compared performing one-way ANOVA using SPSS for Windows Release 10.0.5 (1999) Standard Version (SPSS, Inc., Chicago, IL). Tukey's HSD test was employed for comparison of means where significant differences occurred between days. For wax means, one-way ANOVA was performed to compare the means of 13 treatment-day combinations. Tukey's HSD test was employed for comparison of means where significant differences occurred between combinations. The significant differences were determined at $P<0.05$.

\section{Results and discussion}

\subsection{Thermal transition temperatures of carnauba and grain sorghum waxes}

Thermal transition temperatures of carnauba and grain sorghum waxes were measured to determine similarities in thermal properties. The DSC curves for carnauba and sorghum waxes were considerably different (Figure 1). Transition peak of carnauba wax was wider than that of sorghum wax and had a shoulder on the left slope of the peak. Thermal transition onset, apex and end temperatures of carnauba wax were $73.6^{\circ} \mathrm{C}\left( \pm 0.1{ }^{\circ} \mathrm{C}\right), 86.5^{\circ} \mathrm{C}\left( \pm 0.1^{\circ} \mathrm{C}\right)$, and $88.4^{\circ} \mathrm{C}$ $\left( \pm 0.1^{\circ} \mathrm{C}\right)$, respectively, whereas those of grain sorghum wax were $77.0^{\circ} \mathrm{C}\left( \pm 0.1^{\circ} \mathrm{C}\right), 83.6^{\circ} \mathrm{C}\left( \pm 0.2^{\circ} \mathrm{C}\right)$, and $86.3^{\circ} \mathrm{C}\left( \pm 0.2^{\circ} \mathrm{C}\right)$. Carnauba wax started melting at a lower temperature and ended melting at a higher temperature than grain sorghum wax. The difference in thermal transitions of the two waxes was attributed to the totally different compositions of the two waxes (Hwang et al., 2002a, 2002b). Wax esters are the major components in carnauba wax, whereas aldehydes and alcohols are the major components in sorghum wax. The fact that sorghum wax has a narrower melting temperature range than carnauba wax would give advantage to sorghum wax in applications where a fairly defined melting or softening temperature is desirable.

\subsection{Composition and thermal transition temperatures of aldehyde fraction from sorghum wax during storage}

The aldehyde fraction, separated from wax using column chromatography, was dissolved in hexane or chloroform, and the solvent was removed (aldehydes were eluted with chloroform plus a small amount of hexane in column chromatography; Hwang et al., 


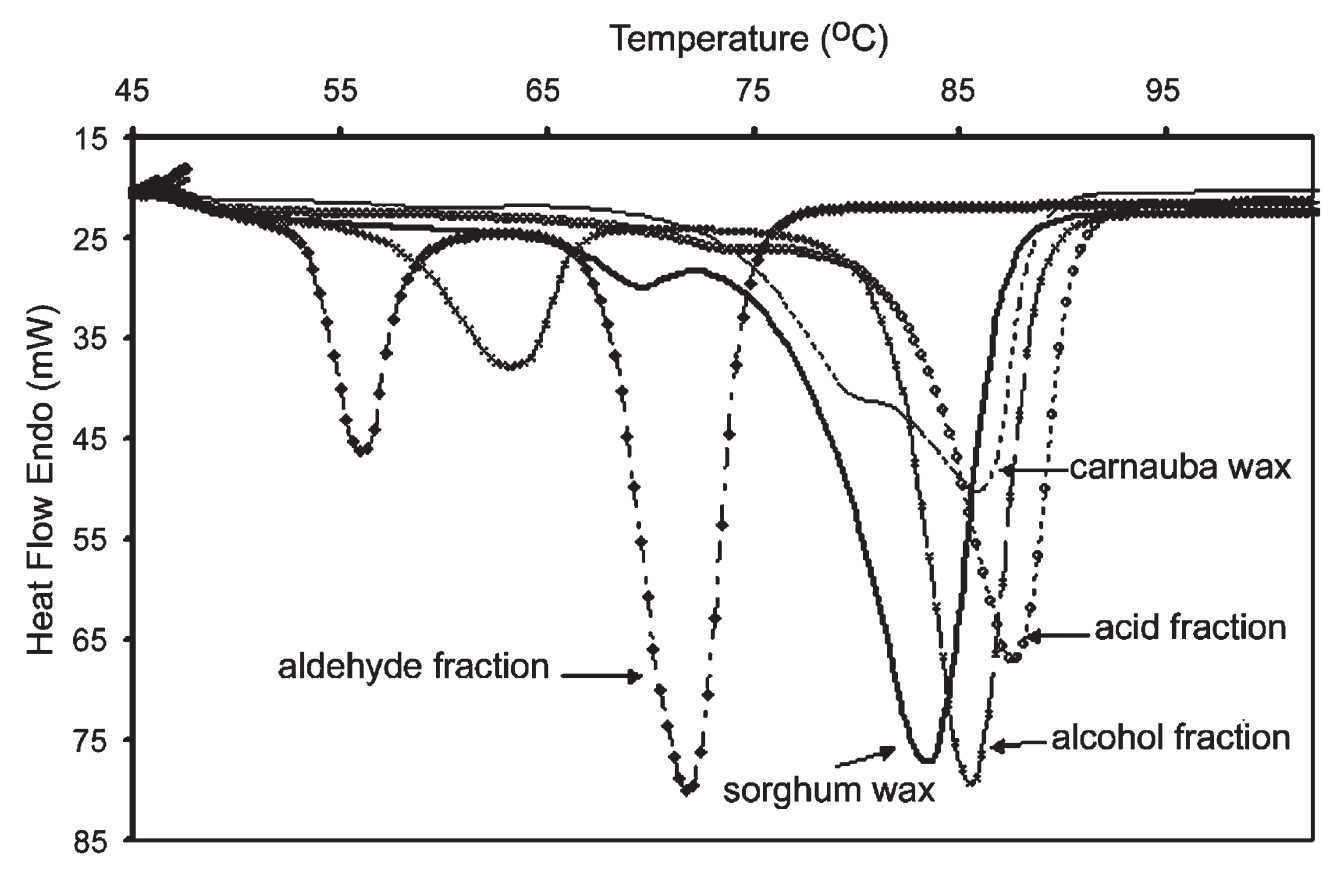

Figure 1. DSC curves of carnauba wax, sorghum wax, and major fractions of sorghum wax.

2002a). When the fractionating solvent (mostly chloroform) was removed from the aldehyde fraction, a faster oxidation of the fraction was noticed in a preliminary study, compared with the aldehyde fraction that was desolvented, redissolved with hexane, and desolvented again. This was the reason for redissolving the aldehyde fraction in hexane and in chloroform for comparison, and the reason for redissolving sorghum wax in chloroform.

The hexane and chloroform redissolved aldehyde fractions (Ald-Chl) initially contained 5 and $6.8 \%$ acids, respectively, and the rest was aldehydes (Table 2). Acid content increased slowly at room temperature and in sunlight over the 135 days in storage. The chloroform-redissolved fraction (Ald-Hex) showed significantly $(P<0.05)$ higher acid production than the hexane-redissolved fraction (Ald-Chl) on Day 135, reaching $50.9 \%$ acids in the former and $41.7 \%$ acids in the latter. Whole sorghum wax and aldehyde fraction were more easily dissolved in chloroform than in hexane. The faster oxidation of the chloroform-redissolved aldehyde fraction may have been due to the arrangement of aldehyde groups in a form more exposed to the air when the aldehyde fraction was dissolved once with chloroform than with hexane. Chlo- roform being more polar than hexane might orient the more polar aldehyde groups outwards.

Thermal transition onset, apex, and end temperatures of aldehyde fraction from sorghum wax were initially 68-69, 73-74, and $76-77^{\circ} \mathrm{C}$, respectively (Figure 1). Thermal transition apex temperatures of acid and alcohol fractions were 87.8 and $85.7^{\circ} \mathrm{C}$, respectively. It was expected that the oxidation of aldehydes to acids would increase thermal transition temperatures of the aldehyde fraction with time. However, thermal transition temperatures of aldehyde fraction changed little during 21 days of storage (Table 2, Figure 2), because the conversion level of aldehydes to acids was low. Thermal transition apex and end temperatures of the hexane-redissolved aldehyde fraction increased significantly $(P<0.05)$ during 135 days of storage, with a remarkable increase in acids (Table 2). Onset temperature $\left(66.7^{\circ} \mathrm{C}\right)$ of the hexane-redissolved aldehyde fraction (Ald-Hex) on day 135 was lower than the initial temperature $\left(69.1^{\circ} \mathrm{C}\right)$, showing wider transition peak (Figure 2). Thermal transition onset, apex and end temperatures of the chloroformredissolved aldehyde fraction increased significantly $(P<0.05)$ during 135 days of storage. The chloroformredissolved aldehyde fraction showed significantly $(P$ 


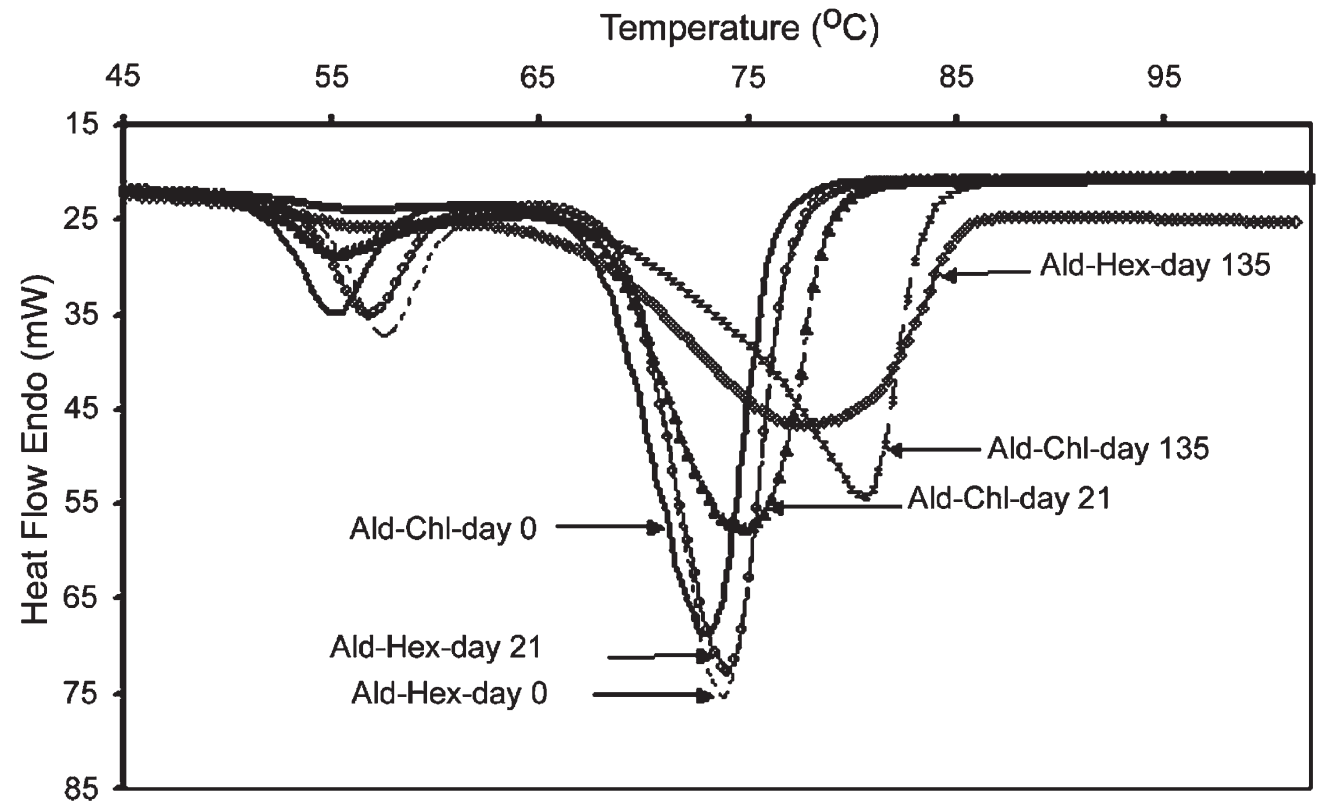

Figure 2. DSC curves of aldehyde fractions during storage at room temperature and in sunlight. See Table 1 for sample codes.

Table 2. Changes in composition and thermal transition temperatures of aldehyde fraction of grain sorghum wax during storage at room temperature in sunlight

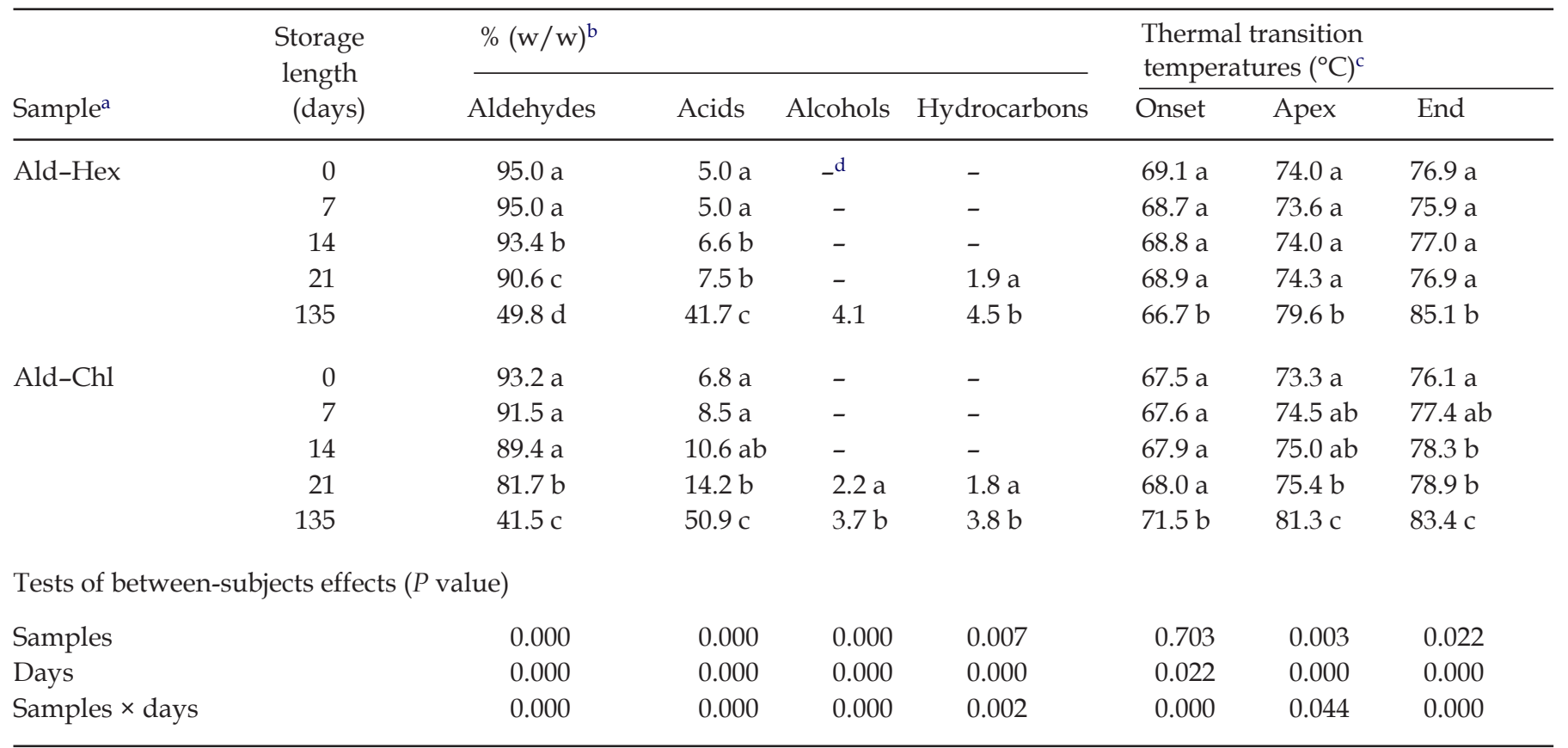

Means in each column in each sample with the same letters a-d are not significantly different $(P \geq 0.05)$.

a See Table 1 for sample codes.

${ }^{\mathrm{b}}$ Mean of three determinations.

${ }^{\mathrm{c}}$ Mean of two determinations.

d Undetectable. 
$<0.05)$ higher thermal transition temperatures than the hexane-redissolved fraction on day 135 and significantly $(P<0.05)$ higher acid level in the chloroformredissolved fraction (Table 2). Industrial users who want higher melting point of a wax may, for example, at some point extract or dissolve sorghum wax in chloroform prior to incorporation in or on a product.

\subsection{Composition and thermal transition temperatures of sorghum wax during storage}

The sorghum wax sample, for the storage test, was initially composed of $55.4 \%$ aldehydes, $7.4 \%$ acids, and $37.2 \%$ alcohols (Table 3 ). The composition of the wax changed little during 5 months of storage in the dark and at room temperature (Wax-R-D). Exposure of the wax to sunlight for about 5 months at room temperature (Wax-R-S) slightly, but significantly ( $P$ $<0.05)$, increased the oxidation of aldehydes to acids (Table 3).

Hydrocarbons were not detected in the samples stored at room temperature (Wax-R-D and Wax-RS) except for the sample stored in sunlight (Wax-R-S) for about 5 months. Storage of the wax at $45^{\circ} \mathrm{C}$ for 42 days in the dark (Wax-A-H) did not notably affect the composition of the wax. The sorghum wax tested in the study was originally extracted with hexane. The aldehyde fraction of sorghum wax redissolved with chloroform (Ald-Chl) reached higher levels of acids sooner than hexane-redissolved aldehyde fraction (Ald-Hex) (Table 2) as discussed previously. However, whole wax did not show a noticeable difference in composition based on the redissolving solvents (Table 3). Sorghum wax stored at the elevated temperature $\left(45^{\circ} \mathrm{C}\right)$ in the dark (Wax-A-H) for about 5 months showed a slight significant $(P<0.05)$ increase in acids and produced hydrocarbons (Table 3). Hydrocarbons were not detected in the wax sample that was redissolved in chloroform and stored at the elevated temperature (Wax-A-C) for about 5 months.

The observed difference in acid formation between grain sorghum wax and the aldehyde fraction over time most likely can be attributed to the exposed area of the material to air. Assuming the wax and fraction were both in a powder form and of relatively the same particle size, proportionally more aldehydes in the aldehyde fraction would be exposed to air than aldehydes in the grain sorghum wax. In the wax, aldehydes are commingled with alcohols, acids, and other components such that less is exposed to air leading to

Table 3. Changes in composition and thermal transition temperatures of grain sorghum wax during storage

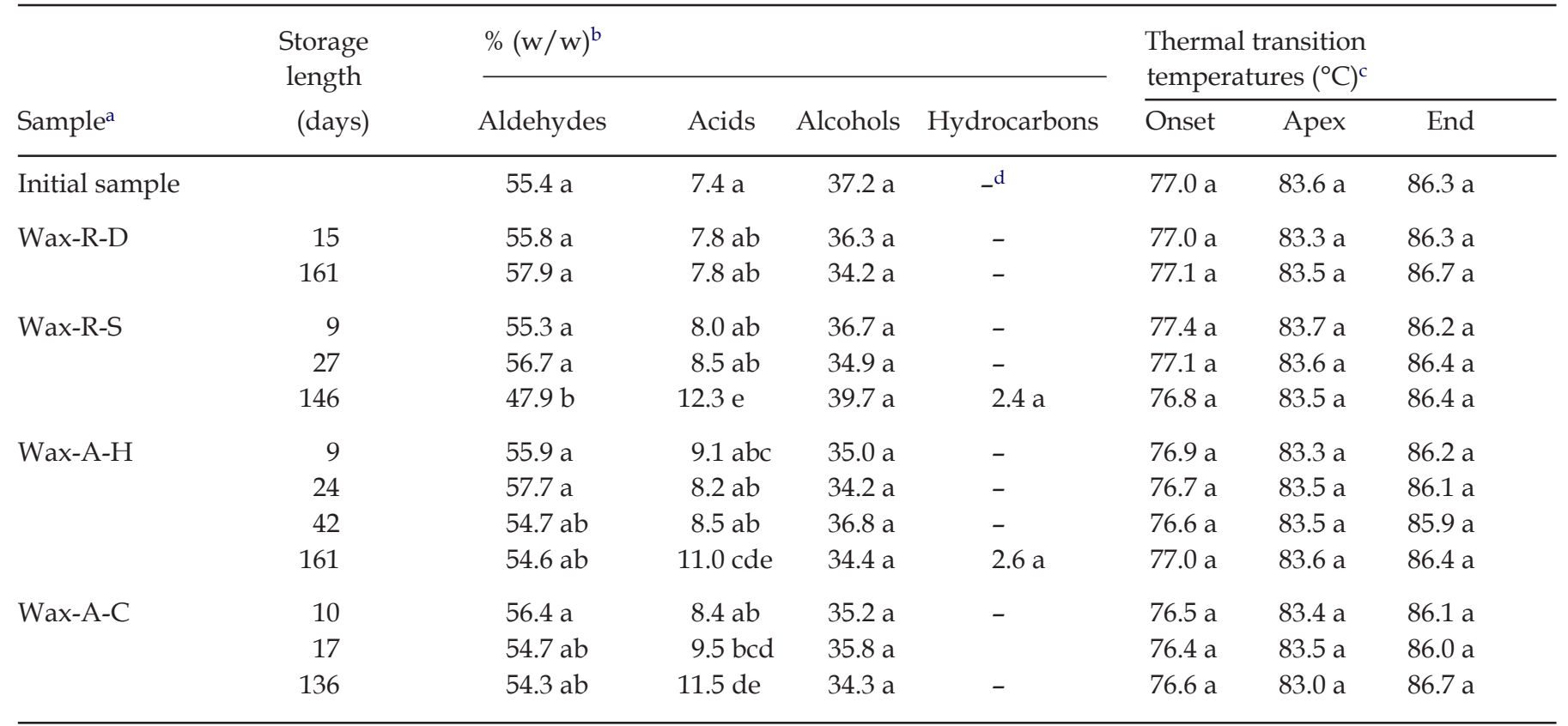

Means in each column with the same letter a-e are not significantly different $(P \geq 0.05)$.

a See Table 1 for sample codes.

${ }^{\mathrm{b}}$ Mean of three determinations.

${ }^{\mathrm{c}}$ Mean of two determinations.

d Undetectable. 
less oxidation than in the aldehyde fraction. Further research is necessary to confirm this postulation.

Minor changes in composition of the whole sorghum wax during storage did not significantly $(P \geq 0.05)$ influence the thermal transition temperatures of the wax, which ranged between 76.4 and $77.4^{\circ} \mathrm{C}$ for onset, 83.0 and $83.7^{\circ} \mathrm{C}$ for apex, and 85.9 and $86.7^{\circ} \mathrm{C}$ for end, over all storage conditions (Table 3). This implies that sorghum wax has stable melting properties during storage for up to 5 months at room and elevated temperatures. Quality factors for final products that are dependent on stability of sorghum wax over time should be consistent. Further study is needed on performance of sorghum wax in products such as coatings and cosmetics. When a wax with a higher melting point is needed, one procedure for increasing it might be by developing a method to oxidize aldehydes to acids in sorghum wax.

\section{Conclusion}

The aldehyde fraction separated from sorghum wax showed notable conversion to acids and changes in the thermal transition temperatures during storage. In whole grain sorghum wax, however, a minor change in chemical composition of the wax was observed without affecting the thermal transition temperatures of the wax. It is noteworthy to mention that sorghum wax was very stable during storage even though it contained a large amount of aldehydes. This study will facilitate the utilization of sorghum wax for human and industrial uses by increasing the understanding of chemical and physical changes in grain sorghum wax during storage. Although sorghum wax is different from carnauba wax in composition, it has similar melting characteristics. The differences of sorghum wax over carnauba wax may provide advantages in industrial uses. Examining functional properties of sorghum wax, especially as a substitute for carnauba wax in part, industrial uses need to be the next research area of sorghum wax.

\section{Acknowledgments}

The research was supported in part by research funds of Chonbuk National University. This article is recorded as Journal Series no. 13986, Agricultural Research Division, Institute of Agriculture and Natural Resources, University of Nebraska-Lincoln.

\section{References}

ASTM, $2000 \varangle$ ASTM, 2000. Standard test method for measurement of transition temperatures of petroleum waxes by differential scanning calorimetry (DSC): D 4419-90. In: Annual Book of ASTM Standards 2000. The American Society for Testing and Materials, vol. 05.02. West Conshohocken, PA, 2000, pp. 878-880.

Avato et al., $1990 \varangle$ P. Avato, G. Bianchi, and C. Murelli, Aliphatic and cyclic lipid components of sorghum plant organs. Phytochemistry 29 (1990), pp. 1073-1078.

Bianchi et al., 1979 G. Bianchi, P. Avato, and G. Mariani, Composition of surface wax from sorghum grain. Cereal Chem. 56 (1979), pp. 491-492.

Bunger and Kummerow, $1951<$ W. B. Bunger and F. A. Kummerow, A comparison of several methods for the separation of unsaponifiable material from carnauba and grain sorghum waxes. J. Am. Oil Chem. Soc. 28 (1951), pp. 121-123.

Cannon and Kummerow, $1957 \varangle$ C. Cannon and F. A. Kummerow, A comparison of plant and grain wax from two varieties of sorghum. J. Am. Oil Chem. Soc. 34 (1957), pp. 519-520.

Dalton and Mitchell, 1959 J. L. Dalton and H. L. Mitchell, Fractionation of grain sorghum wax. Ag. Food Chem. 7 (1959), pp. 570-573.

Hamilton, 1995a 4 R. J. Hamilton, Commercial waxes: their composition and applications. In: Hamilton, R.J. (Ed.), Waxes: Chemistry, Molecular Biology and Functions, vol. 6. Oily Press, Dundee, Scotland, 1995, pp. 257-310.

Hamilton, 1995b $\varangle$ R. J. Hamilton, Analysis of waxes. In: Hamilton, R. J. (Ed.), Waxes: Chemistry, Molecular Biology and Functions, vol. 6. Oily Press, Dundee, Scotland, 1995, pp. 311-342.

Hwang et al., 2002a 4 K. T. Hwang, S. L. Cuppett, C. L. Weller, M. A. Hanna, and R. K. Shoemaker, Aldehydes in grain sorghum wax. J. Am. Oil. Chem. Soc. 79 (2002), pp. 529-533.

Hwang et al., 2002b 4 K. T. Hwang, S. L. Cuppett, C. L. Weller, and M. A. Hanna, HPLC of grain sorghum wax classes highlighting separation of aldehydes from wax esters and steryl esters. J. Sep. Sci. 25 (2002), pp. 619-623.

Linstromberg and Baumgarten, $1974 \varangle$ W. W. Linstromberg and H. E. Baumgarten, Reactions of Aldehydes and Ketones. In: Organic Experiments, third ed. D.C. Heath and Co., Lexington, MA, 1974, pp. 119-128.

Lochte-Watson et al., $1999 \varangle$ K. R. Lochte-Watson, C. L. Weller, and S. L. Cuppett, Wax Extraction Parameters of Whole Grain Sorghum Kernels and Bran. Paper No. 99-6125. American Society of Agricultural Engineers, St. Joseph, MI, 1999.

Seitz, $1977<$ L. M. Seitz, Composition of sorghum grain wax. Cereal Foods World 22 (1977), p. 472.

Weller et al., $2000 \triangleleft$ C. L. Weller, S. L. Cuppett, L. C. Hua, K. R. Lochte-Watson, C. Gaudoin, J. Arrault, C. M. Hubbard, and J. P. Mua, Solvent Influence on Yield and Fractions of Grain Sorghum Wax. Paper No. 00-6134. American Society of Agricultural Engineers, St. Joseph, MI, 2000. 